\title{
A Critical Analysis of Risk Factors for Selected Tropical Diseases
}

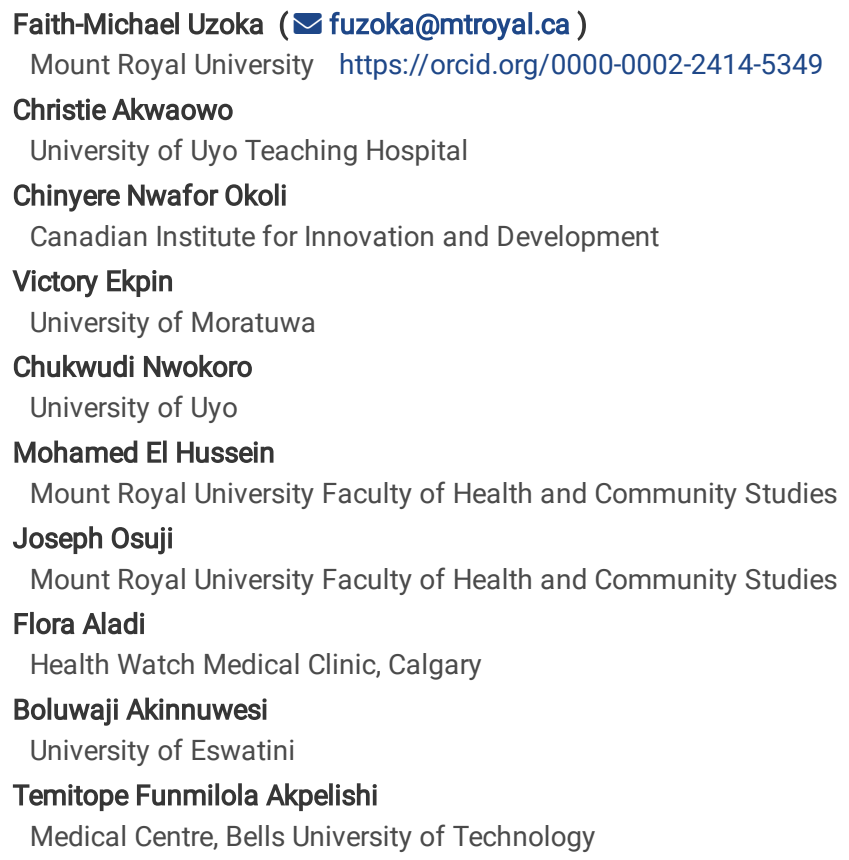

Research article

Keywords: Risk factor, Infectious diseases, Tropical diseases, Communicable diseases and Sub-Saharan Africa

Posted Date: March 31st, 2021

DOl: https://doi.org/10.21203/rs.3.rs-368794/v1

License: (c) (1) This work is licensed under a Creative Commons Attribution 4.0 International License. Read Full License 


\section{Abstract}

Aim: The aim of this study was to examine the impacts of different (non-clinical) risk factors on the populations' predisposition to tropical diseases specifically Malaria, yellow fever, typhoid fever, chicken pox, measles, hepatitis B and UTI.

Subject and Methods: Data for this study was obtained through patient diagnosis forms, distributed to physicians in Nigeria. A total of 2199 patient consultation forms were returned by 102 (out of 125) physicians, and considered useful for analysis. Demographic data of patients, physicians, and diagnosis outcomes were analysed descriptively through frequency distributions, aggregate analysis, and graphs, while the influence of risk factors on the disease manifestations (diagnosis outcomes) were determined using regression analysis.

Results: Findings from our study demonstrated that the difficulty in diagnosing tropical disease was associated with significant increase in morbidity and mortality especially in patients with malaria, UTI and typhoid fever. Factors such as contact with an infected person and poor personal hygiene posed significant risk, while urbanization and homelessness, posed very low risks across all the diseases.

Conclusion: The risk factors identified in our study exert differential and discriminating influences in the causation, predisposition, and transmission of these conditions, understanding the individual risk factors for each condition have significant socio-economic implications for people living in tropical and endemic regions, especially with respect to management and prevention of these conditions.

\subsection{Introduction}

Tropical diseases are a diverse group of infectious diseases that are endemic in tropical and subtropical regions. They are usually caused by pathogens like viruses, bacteria, and parasites. Unfortunately tropical diseases tend to be 'neglected' as they typically affect people in low socioeconomic classes, with poor sanitary and housing conditions as well as people in areas that typically have difficult access to health services (WHO EMRO, 2020). Tropical diseases represent a major public health problem and as such have started drawing the attention of international health organizations because of the difficulty associated with early diagnosis and the high mortality rates associated with them when they go untreated (Uzoka et al., 2016; WHO EMRO, 2020).

A number of these tropical diseases have confusable symptoms. This is particularly important because tropical diseases are no longer localized in tropical regions due to globalization of trade and increased travel to and from endemic regions (Obot et al., 2014). These diseases could present a diagnostic challenge to physicians especially in non-endemic areas. An understanding of the various risk factors for tropical diseases can give further insights into the diagnosis. Besides, research has shown that risk factors to a particular disease could change over time. It has been established that a substantial epidemiological shift occurred in the contribution of different risk factors to disease burden within 1990-2010(Lim et al., 2012). This type of understanding is important to inform accurate policies, decision making, and intervention.

The aim of this study is to develop a system for the understanding and differential diagnosis of tropical diseases. In this study, we analysed risk factors associated with some tropical diseases that are prevalent in Nigeria, the most populous sub-Saharan African country. We also examined the various factors associated with increased risk of having various tropical diseases including malaria, typhoid fever, chicken pox, measles, hepatitis B, yellow fever and urinary tract infections. The manuscript is arranged as follows: Sect. 1 presents the introduction. In Sect. 2, we present relevant literature on tropical diseases risk factors, while the methodology of our study is described in Sect. 3. The results are presented in Sect. 4 and discussed in Sect. 5, while some conclusions are drawn in Sect. 6.

\subsection{Literature Review}

Malaria is one of the most common tropical diseases with about 3.2 billion of the world's population at risk of the disease (Abossie et al., 2020). Malaria is a life-threatening illness caused by parasites that are transmitted to people through the bites of infected female Anopheles mosquitoes. It is mainly transmitted in tropical and sub-tropical areas, especially the WHO African region (WHO, 2020a). An efficient system for malaria transmission requires strong interaction between the hosts, the ecosystem and infected vectors. Most of the risk factors for malaria are therefore environmental. The most important of these risk factors is said to be the tropical climate which is characterized by average monthly temperatures above $18^{\circ} \mathrm{C}$ (Henry, 2005). (Mohammadkhani et al., 2016) reported that a $1^{\circ} \mathrm{C}$ increase in maximum temperature in a given month was related to a $15 \%$ and $19 \%$ increase in malaria incidence on the same and subsequent month, respectively. The humidity and rainfall of tropical regions are also responsible for malaria endemicity in these regions (Kotepui \& Kotepui, 2018). Travel from a non-endemic to an endemic region therefore increases the risk of contracting malaria as individuals with no natural immunity are inevitably exposed to the disease in these areas (Pinsent et al., 2014).

Open canals, as well as ditches and water puddles act as vector breeding sites, thereby increasing malaria transmission. Nearness of houses or communities to open canals and poor housing structure are therefore risk factors for malaria (De Silva \& Marshall, 2012; Thang et al., 2008). For the same reason, nearness of houses to urban agricultural lands with agricultural trenches and sprinkler irrigation system has been linked to increased risk of malaria (Chimbari et al., 2004; De Silva \& Marshall, 2012). A study in central Vietnam linked low socioeconomic class to be an important risk factor for malaria. It was opined that this was possibly because of poorer housing conditions increasing their exposure to infective bites within their villages, and the fact that those of lower socioeconomic class were more likely to make regular visits to and even sleep in forests (Thang et al., 2008). In this case, poverty can therefore be said to act as the middleman, linking different risk factors for malaria. A higher socioeconomic status is associated with better housing structures, situation of houses in better environments, ability to afford prevention methods, and better refuse collection among others, all of which reduce the risk of malaria infection (De Silva \& Marshall, 2012). 
Another tropical disease of significant public health importance is typhoid fever, also called enteric fever. It is a systemic bacterial illness transmitted from person to person via the feco-oral route (Mogasale et al., 2018). Several factors have been linked to risk of having typhoid fever. Studies have linked domestic use of contaminated water to incidence of enteric fever (Deksissa \& Gebremedhin, 2019; Mogasale et al., 2018). A systematic literature review over a 23-year period reported that the odds of typhoid fever among those exposed to unsafe water ranged from 1.06 to 9.26 with case weighted mean of 2.44 (Mogasale et al., 2018). Urbanization in tropical regions and the resultant increase in number of people living in urban slums with unsanitary facilities and poor access to clean water due to government neglect to provide potable water, coupled with poor municipal waste management predisposes the people to use fecally contaminated water for food preparation and drinking. This is worsened by the indiscriminate drilling of boreholes by house owners in the region, which gives them access to ground water, often times polluted due to unplanned situation of sewage drainages (Omole et al., 2010).

Consumption of raw vegetables, meat, seafood and milk which are often times contaminated with excreta of an infected person have also been shown to increase the risk of widal test seropositivity (Deksissa \& Gebremedhin, 2019; Hosoglu et al., 2006). Another risk factor that has been associated with development of enteric fever is the consumption of street vended foods (Alba et al., 2016). Akuu et al reported that those who ate out in food stalls were 6.9 times more likely to have typhoid fever. This finding was attributed to poor hygiene maintained by commercial food vendors as they have little to no regulation in most tropical regions (Akuu et al., 2017; Okojie \& Isah, 2014).

Primary infection with varicella-zoster virus (VZV), also called chickenpox, is usually considered a disease of childhood that has few complications with a low case fatality rate in healthy children. However, it can be serious or sometimes fatal in immune compromised patients, infants, adolescents, adults and pregnant women (WHO, 2018b). Although varicella occurs worldwide, the epidemiology of the disease is recognized as being different in temperate and tropical regions. In temperate regions, varicella is a disease of preschool and school-age children (Socan et al., 2010; van Rijckevorsel et al., 2012). In tropical regions, varicella typically occurs at a later age (Daulagala \& Noordeen, 2018; Mandal et al., 1998) with many cases in adolescents and adults who are at risk of developing more severe disease.

The epidemiology of Varicella zoster is incompletely understood in tropical and subtropical regions, though various hypotheses have been proposed to explain the different age distribution. Climatic factors, socioeconomic conditions, mobility and cultural practices seem to play a role in the differences in the exposure rates to Varicella zoster virus infection in the tropics (Daulagala \& Noordeen, 2018). The age distribution of varicella in tropical regions varies with place of residence. Fernando et al documents that while seroprevalence rates increased with age in both the rural and urban populations, seroprevalence rates of VZV infections were significantly different between the urban and rural populations $(P<0.001)$ Other studies document similar findings. (Fernando et al., 2007; Mandal et al., 1998; Tanthiphabha et al., 2000). The most likely explanation for this is population density. In urban settings, higher population densities may somewhat overcome the transmission-interrupting effect of a tropical climate.

Measles is a highly contagious disease with potentially life-threatening complications. It contributed to a significant number of childhood deaths before the introduction of the measles vaccine (Weisberg, 2007). It is spread from person to person when an infected person talks, coughs or sneezes. It can also be contracted through contact with mucus or saliva from an infected person. Researchers have found the risk factors for measles to include age less than 24 months, absent or incomplete Mumps-Measles-Rubella vaccination, travel to countries with measles outbreaks and immune deficiency (Odei, 2018; Vemula et al., 2016). (Hagan et al., 2017 in a study on risk factors for measles during a large outbreak in Mongolia found that those who were not vaccinated had a 2fold risk of being infected compared to those who were vaccinated. He also reported that contact with an inpatient healthcare facility during the month before rash onset was an independent risk factor for measles, increasing the risk about 4.5 times. This points to how contagious the disease is. It stands to reason that overcrowding and high population density would lead to an increased risk of measles infection. Transmission of measles in displaced populations and associated factors, the highest incidence rates was described for Vietnamese children in Hong Kong camps where housing was cramped, consisting of huts that housed approximately 250 refugees (Kouadio et al., 2010). It can therefore be said that factors associated with increased measles transmission are those that cause increased contact with infected persons or those that reduced natural or acquired immunity.

The yellow fever virus, also endemic in tropical and subtropical areas of Africa and South America is spread through the bite of an infected mosquito. Most infected persons experience no or mild symptoms and only a small proportion develop severe symptom, with a very high fatality rate (WHO, 2020b). Large epidemics of yellow fever occur when infected people introduce yellow fever virus into heavily populated areas with high mosquito density and where most people have little or no immunity due to insufficient vaccination (WHO, 2020b). Factors that increase the risk of yellow fever infection are therefore related to high population density, environmental factors that support vector proliferation and poor immunity to the virus. Since the yellow fever vaccine became available in the 1930s, the combination of vaccination and vector control strategies has led to plausible decrease in disease burden in some geographical locations (Shearer et al., 2018). However, since mass vaccination campaigns may not reach all of the population, sporadic cases in a vaccinated population can still occur, but transmission rates are usually low and do not amplify into epidemic transmission (Barnett, 2007).

Unvaccinated travellers visiting endemic areas have been found to have higher risk of acquiring and dying from yellow fever (Hamer et al., 2018). The virus can also be carried into a nonendemic area by a traveller. The ecoclimatic conditions in the tropical region, including temperature, rainfall, and humidity, favour the survival of the mosquitos, long enough for the virus to disseminate in the mosquito to allow onward transmission as the incubation period of the virus in the mosquito is largely dependent on temperature and humidity (Chen \& Wilson, 2020). Low socioeconomic class has also been linked to increased risk of yellow fever infection. This has been attributed to the fact that those in higher wealth groups are more likely to receive yellow fever vaccination compared to those in lower wealth groups (Aremu, 2018). This can also be explained by better vector control strategies seen in wealthier neighbourhoods compared to poorer neighbourhoods (De Silva \& Marshall, 2012; Thang et al., 2008).

Urinary tract infections (UTI) are among the most common infections throughout one's lifespan, irrespective of gender (Flores-Mireles et al., 2015). Risk factors for recurrent UTIs could be anatomical, behavioural, or immune-related. Generally, females have been found to have a higher risk of UTIs compared to males (Flores-Mireles et al., 2015; Foxman, 2014). This has been linked to their shorter urethra and the close proximity of the urethra to the vagina and anus 
which can lead to translocation of organisms (Minardi et al., 2011). However, infant boys and elderly men are also at high risk of having recurrent UTIs due to anatomical factors. Infant boys have higher rates of urinary tract anomalies compared to infant females which could predispose them to recurrent UTIs (Keren et al., 2015), and elderly men are at risk of having urinary retention due to prostatic hypertrophy and partial obstruction (Speakman \& Cheng, 2014). Research has shown an increased risk of UTIs with increased frequency of sexual intercourse more than 3 times a week, voluntary retention of urine and reduced water intake (Amiri et al., 2009; Storme et al., 2019).

A number of genital hygiene practices have also been associated with increased risk of UTI, including washing of genitals post coitus, frequency of baths, and types of underwear. (Amiri et al., 2009) reported that women with UTIs in their study took baths and replaced their underwear significantly less often than the controls. They also wore non-cotton pants more often than the controls. Immunocompromised individuals such as those with diabetes mellitus, HIV/AIDS, or individuals on immunosuppressive drugs are at higher risk of having UTIs (Minardi et al., 2011). In addition, the presence of urological conditions such as urinary incontinence, neurogenic bladder, bladder stones, and prolonged catheterization have been found to predispose to recurrent UTI. (Storme et al., 2019)

Hepatitis B is a viral infection of the liver caused by hepatitis B virus (HBV). Although HBV is endemic globally, a significant proportion of the disease burden is now borne by countries in tropical and subtropical regions (Lemoine et al., 2013). HBV infection is transmitted through exposure to blood, semen, other body fluids of infected persons, or through vertical transmission at the time of birth. Transmission may also occur through transfusions of HBV-

contaminated blood and blood products, contaminated injections during medical procedures, and through injection drug use (Ayele \& Gebre-Selassie, 2013). Several traditional practices seen in some African countries, especially in sub-Saharan Africa such as traditional scarification and tattooing, circumcision by traditional healers, and female genital mutilation have high possibilities of infection transmission including hepatitis $B$. This is because instruments are typically used and reused without the observation of standard sterilization measures (Eke et al., 2015). Socio-economic status has also been found by some researchers influence risk of HBV infection (Eke et al., 2015; Ugwuja \& Ugwu, 2010). They opined that the reason for this may be that people from low socioeconomic backgrounds are more likely to be exposed to sources of HBV acquisition including routes like circumcision in unsanitary places, and scarification with un-sterilized blades among others.

About two decades ago, communicable, maternal, perinatal, and nutritional disorders explained $43.9 \%$ of all causes of death and disability, while noncommunicable causes explained $40.9 \%$ (Murray \& Lopez, 1997). Nevertheless, recent times have seen a drastic change in the leading causes of death and disability worldwide from communicable towards non-communicable diseases (Vos et al., 2020). These broad global patterns mask enormous regional variation in risks to health. In sub-Saharan Africa, risks such as childhood underweight, household air pollution, and micronutrient deficiency continue to cause a disproportionate amount of health burden, despite decreasing (Vos et al., 2020). Majority of individuals and communities in tropical regions who are have high risk of infectious diseases have poor access to the resources necessary to address the social determinants of these diseases. They may live in unsanitary conditions, with poor nutrition, and lack of access to necessary health care systems for treatment, despite many of these diseases being preventable and/or treatable through specific interventions (Mackey et al., 2014).

The risk factors for tropical diseases are different from those of non-communicable diseases in that the risk of non-communicable diseases are mainly related to individual lifestyle and often reflect the choices of persons such as physical inactivity, high calorie diets, alcohol use and cigarette smoking (Vos et al., 2020). Similar to communicable diseases however, the importance of assessment of the risk factors for infectious diseases cannot be over emphasized as it helps to narrow down the diagnosis. Assessing for risk factors to diseases also gives opportunity for risk factor modification in order to prevent future recurrences of these diseases (Dovjak \& Kukec, 2019).

\subsection{Methodology}

\section{Data Collection}

Data for this study was obtained through patient diagnosis forms, distributed to physicians in Nigeria. Twenty patient consultation forms were distributed to each of 125 physicians, who were randomly selected from the northern, western and eastern/southern Nigeria. The patient data collection form had five sections: Section A contained demographic information about the patient and the attending physician; Section B obtained information about clinical presentations (symptoms) and risk factors based on patient consultation; Section C gave the physician the opportunity to indicate suspected diseases (hypotheses); Section D contained further investigation information, while Section E showed the final diagnosis, which is was based on the clinical presentations and further investigation.

The tool was developed by the researchers. These surveys were validated by establishing the survey's face value by experts, the survey was pilot tested on a subset of participants. These pilot data were analysed included using PCA and CA methodology.

Ethical clearance was sought and obtained from Mount Royal University Human Research Ethic Board. Patient consent was sought prior to utilization of the data collection form during patient consultation. There was no age or gender restriction regarding patients who participated in the study; however, to ensure that minors were protected from undue influence, only minors (ages 0-17) whose parents consented to participation in the study were included. In addition, a minor's assent was required to participate in the study. Data collection was entirely anonymous, and completed forms were returned without any respondent's or patient's identification information. A total of 2199 patient consultation forms were returned by 102 physicians, and considered useful for analysis.

\section{Data Analysis}

The Statistical Package for Social Sciences (SPSS) version 20.0 was utilized in the analysis of data. Demographic data of patients, physicians, and diagnosis outcomes were analysed descriptively through frequency distributions, aggregate analysis, and graphs, while the influence of risk factors on the 
disease manifestations (diagnosis outcomes) were determined using regression analysis.

A weighting of the disease prevalence by the physicians was carried out using the aggregation formula adapted from Uzoka and Ndzinge (2009):

$$
\text { Weighted Prevalence }=\frac{\sum_{i=1}^{5} w_{i} p_{i}}{5}
$$

where $w_{i}$ is the weight assigned to $i^{\text {th }}$ level of intensity of attack of a given disease. The intensity ranges from very low $\left(w_{i}=1\right)$ to very high $\left(w_{i}=5\right)$; $P i$ is the percentage of patients diagnosed with the given disease, with intensity of attack i. Note that some patients were diagnosed with multiple diseases at different levels of intensity of attack. The prevalence percent is computed relative to all the weighted prevalence values.

SPSS also computes the collinearity statistics (the tolerance and variance inflation factor [VIF]) to determine if two variables are near perfect linear combinations of one another. As the degree of collinearity increases, the regression model estimates of the coefficients become unstable. The "tolerance" is an indication of the percent of variance in the predictor that cannot be accounted for by the other predictors, hence very small values indicate that a predictor is redundant. Ideally the tolerance should be greater than 0.5 , while the VIF should be 5 or less.

\subsection{Results}

Table 1 shows the demographic information on the patients, the physicians who conducted the diagnosis and the weather season when the patient consultation /diagnosis was conducted. The sample consisted of $52.6 \%$ females and $47.4 \%$ males, who were mostly below 40 years (76.5\%), while most of the diagnosis $(63.4 \%)$ were carried out by experienced physicians (over 5 years). The levels of experience of the physicians point to their ability to clearly understand the dynamics of tropical diseases. The final diagnosis outcomes were arrived at through further tests that were conducted on the patients to determine the actual disease(s) and their intensity levels. $60 \%$ of the diagnoses were conducted in the dry season, while the rest were either in the rainy or harmattan seasons

Table 1: Demographic Information

\begin{tabular}{|c|c|c|c|}
\hline & & Valid frequency & Percent \\
\hline \multirow[t]{2}{*}{ Patient Gender } & Male & 1038 & 47.4 \\
\hline & Female & 1150 & 52.6 \\
\hline \multirow[t]{7}{*}{ Patient age (years) } & $\leq 10$ & 438 & 19.9 \\
\hline & 20-Nov & 401 & 18.2 \\
\hline & $21-30$ & 555 & 25.2 \\
\hline & $31-40$ & 290 & 13.2 \\
\hline & $41-50$ & 288 & 13.1 \\
\hline & $50-60$ & 111 & 5.0 \\
\hline & $>60$ & 116 & 5.3 \\
\hline \multirow[t]{5}{*}{ Diagnosing physician's experience (years) } & $<5$ & 805 & 36.6 \\
\hline & $5-10$ & 565 & 25.7 \\
\hline & $11-15$ & 283 & 12.9 \\
\hline & $16-20$ & 69 & 3.1 \\
\hline & $>20$ & 477 & 21.7 \\
\hline \multirow{3}{*}{ Season } & Rainy season & 381 & 17.3 \\
\hline & Harmattan & 655 & 29.8 \\
\hline & Dry season & 1163 & 52.9 \\
\hline
\end{tabular}

Table 2 shows the weighted and unweighted disease prevalence as diagnosed by the physicians. The final diagnoses were arrived at through further diagnostic tests that were conducted on the patients to determine the actual disease(s) and their intensity levels. A total of 2159 diagnoses were made, the highest unweighted prevalence being malaria (61.3\%), UTI, (19.1\%), typhoid (18.3\%). However, the prevalence of the diseases differed significantly when weighted. The weighting was done using the aggregation formula adapted from Uzoka and Ndzinge (2009):

We aggregated the intensity of disease attack in the diagnosed cases, using the following aggregation formula, adapted from Uzoka and Ndzinge (2009): 
Weighted Prevalence $=\frac{\sum_{i=1}^{5} w_{i} p_{i}}{5}$

where $w_{i}$ is the weight assigned to $i^{\text {th }}$ level of intensity of attack of a given disease. The intensity ranges from very low $\left(w_{i}=1\right)$ to very high $\left(w_{i}=5\right)$; $p i$ is the percentage of patients diagnosed with the given disease, with intensity of attack i. Note that some patients were diagnosed with multiple diseases at different levels of intensity of attack. The prevalence percent is computed relative to all the weighted prevalence values. Table 2 shows the overall prevalence and intensities. This is further visualized in Figures 1 and 2 in terms of the intensities of attack as revealed in the final diagnosis, and the percentage prevalence.

Table 2: Disease Prevalence based on diagnosis

\begin{tabular}{|c|c|c|c|c|c|c|c|c|}
\hline \multirow[t]{2}{*}{ Disease } & \multicolumn{6}{|l|}{ Intensity of attack } & \multirow[t]{2}{*}{ Weighted prevalence } & \multirow[t]{2}{*}{ Prevalence percent } \\
\hline & Percent diagnosed & Very low & Low & Moderate & High & Very High & & \\
\hline Malaria & 61.30 & 3.40 & 8.00 & 14.10 & 25.10 & 10.70 & 43.12 & $47.91 \%$ \\
\hline Typhoid & 18.30 & 0.80 & 3.00 & 9.00 & 3.70 & 1.70 & 11.42 & $12.69 \%$ \\
\hline Chicken Pox & 7.20 & 0.10 & 0.20 & 4.60 & 2.10 & 0.30 & 4.84 & $5.38 \%$ \\
\hline Measles & 1.30 & 1.20 & 0.10 & 0.00 & 0.00 & 0.00 & 0.28 & $0.31 \%$ \\
\hline Hepatitis B & 3.30 & 1.00 & 0.40 & 1.70 & 0.10 & 0.10 & 1.56 & $1.73 \%$ \\
\hline Yellow Fever & 0.70 & 0.10 & 0.20 & 0.10 & 0.40 & 0.00 & 0.48 & $0.53 \%$ \\
\hline UTI & 19.10 & 3.10 & 0.50 & 0.90 & 7.80 & 6.70 & 14.30 & $15.89 \%$ \\
\hline Other & 18.40 & 0.00 & 2.70 & 3.20 & 7.50 & 5.00 & 14.00 & $15.56 \%$ \\
\hline
\end{tabular}

The results clearly indicate that malaria was the most commonly diagnosed disease, followed by UTI, and typhoid. Malaria also with had the highest levels of intensity of 14.1 moderate, 25.1 high and 10.7 very high. A total of $61.32 \%$ of the patients were diagnosed with malaria; $49.9 \%$ of which had moderate to very high intensity of attack, while $11.4 \%$ had low intensity. The second and third in level of prevalence were UTI and typhoid fever, with intensity weights of 14.32 and 11.50 respectively.

\section{Regression Analysis}

We conducted regression analysis to determine the impact of risk (non-clinical) factors on the prevalence of the tropical diseases under consideration. The following risk factors were considered in our study: Low socio-economic status (Lwsocec), immigration (Immig), tropical climate (Tropclim), urbanization new comers (Urbanzatn), street vendor (Strtvend), sewage contamination (Swgcont), poor personal hygiene (Popershy), overcrowding (Ovrcrwd), homelessness (Hmlsness), travel to endemic region (Trendreg), skin puncture procedure (Sknpunproc), direct contact with infected persons (Continfect), low fluid intake (Lowfliud), non-cotton underwear (Noncotund), and lack of voiding (Lackvoid). Tables 3 shows the regression statistics.

The collinearity statistics (Tolerance [Tol] and variance inflation factor [VIF]) show good levels of tolerance [ $>0.2]$ and variance inflation factor (VIF) [ $<5]$ for most of the predictors, relative to each disease (except for low fluid and lack of void, both of which exhibit Tol of 0.18 and 0.2 respectively). The predictive power of the model $\left(\mathrm{R}^{2}\right.$, adjusted $\mathrm{R}^{2}$ ) are generally low. This is not surprising, since the risk factors are not the main determinants in the diagnosis of diseases; the symptoms are.

\section{Table 3: Regression Statistics}




\begin{tabular}{|c|c|c|c|c|c|c|c|c|c|c|c|c|c|c|c|c|c|c|}
\hline & \multicolumn{2}{|c|}{ Malaria } & \multicolumn{2}{|c|}{ Typhoid } & \multicolumn{2}{|c|}{ Chk Pox } & \multicolumn{2}{|c|}{ Measles } & \multicolumn{2}{|c|}{ Hepatitis B } & \multicolumn{2}{|c|}{$\begin{array}{l}\text { Yellow } \\
\text { Fever }\end{array}$} & \multicolumn{2}{|l|}{ UTI } & \multicolumn{2}{|c|}{ Others } & \multirow{4}{*}{$\mathrm{Tol}$} & \multirow{4}{*}{ VIF } \\
\hline $\mathrm{R}^{2}$ & 0.491 & & 0.366 & & 0.647 & & 0.023 & & 0.03 & & 0.037 & & 0.465 & & 0.286 & & & \\
\hline \multirow[t]{2}{*}{ Adjusted $\mathrm{R}^{2}$} & \multicolumn{2}{|l|}{0.487} & \multicolumn{2}{|l|}{0.362} & \multicolumn{2}{|l|}{0.644} & \multicolumn{2}{|c|}{0.016} & \multicolumn{2}{|c|}{0.026} & \multicolumn{2}{|c|}{0.030} & \multicolumn{2}{|c|}{0.461} & \multicolumn{2}{|l|}{0.281} & & \\
\hline & $t$ & $p$ & $t$ & $p$ & $t$ & $p$ & $t$ & $p$ & $t$ & $p$ & $t$ & $p$ & $t$ & $p$ & $t$ & $p$ & & \\
\hline Lwsocec & 7.9 & 0.00 & 0.2 & 0.00 & -6.9 & 0.00 & 1.5 & 0.13 & 0.9 & 0.36 & -2.8 & 0.01 & -1.3 & 0.19 & 6.8 & 0.00 & 0.56 & 1.78 \\
\hline Immig & 7.8 & 0.00 & 7.2 & 0.81 & 15.1 & 0.00 & -1.2 & 0.23 & -3.0 & 0.00 & 0.3 & 0.79 & 1.8 & 0.07 & -10.6 & 0.00 & 0.64 & 1.57 \\
\hline Tropclim & 19.9 & 0.00 & -3.2 & 0.00 & -6.5 & 0.00 & -4.3 & 0.00 & -3.6 & 0.00 & -3.1 & 0.00 & 12.7 & 0.00 & -4.5 & 0.00 & 0.82 & 1.22 \\
\hline Urbanzatn & 1.1 & 0.28 & 3.4 & 0.00 & -6.7 & 0.00 & -1.7 & 0.09 & -2.9 & 0.00 & 1.0 & 0.31 & 1.5 & 0.14 & 2.9 & 0.00 & 0.53 & 1.88 \\
\hline Strtvend & -10.0 & 0.00 & 10.7 & 0.00 & 6.8 & 0.00 & -0.5 & 0.65 & -3.7 & 0.00 & 7.9 & 0.00 & -2.7 & 0.01 & 2.6 & 0.01 & 0.69 & 1.44 \\
\hline Swgcont & 4.5 & 0.00 & 10.7 & 0.00 & -10.1 & 0.00 & 0.0 & 0.98 & 2.7 & 0.01 & -2.0 & 0.05 & -10.9 & 0.00 & 3.6 & 0.00 & 0.46 & 2.17 \\
\hline Popershy & -0.6 & 0.55 & -3.5 & 0.00 & -2.4 & 0.01 & -3.5 & 0.00 & -0.3 & 0.76 & 0.0 & 0.99 & 23.6 & 0.00 & 0.4 & 0.67 & 0.48 & 2.09 \\
\hline Ovrcrwd & -5.2 & 0.00 & 3.1 & 0.00 & 5.6 & 0.00 & 2.3 & 0.02 & 2.1 & 0.03 & 1.1 & 0.26 & -1.8 & 0.07 & 11.2 & 0.00 & 0.65 & 1.54 \\
\hline Hmlsness & 0.3 & 0.75 & 7.6 & 0.00 & -0.1 & 0.88 & -0.3 & 0.79 & -2.2 & 0.03 & -0.2 & 0.83 & -5.0 & 0.00 & -3.2 & 0.00 & 0.57 & 1.74 \\
\hline Trendreg & 11.0 & 0.00 & -10.5 & 0.00 & -7.3 & 0.00 & -2.3 & 0.02 & 1.4 & 0.17 & -0.9 & 0.38 & -5.2 & 0.00 & 6.3 & 0.00 & 0.75 & 1.33 \\
\hline Sknpunproc & -3.2 & 0.00 & 0.3 & 0.00 & 3.6 & 0.00 & -0.5 & 0.65 & 4.0 & 0.00 & -1.4 & 0.15 & -3.3 & 0.00 & -10.0 & 0.00 & 0.83 & 1.21 \\
\hline Continfect & -19.9 & 0.00 & -12.8 & 0.76 & 41.8 & 0.00 & -0.8 & 0.41 & 1.3 & 0.21 & -1.9 & 0.06 & -4.3 & 0.00 & 10.2 & 0.00 & 0.66 & 1.52 \\
\hline Lowfliud & -12.4 & 0.00 & 6.2 & 0.00 & 2.8 & 0.01 & 0.1 & 0.93 & 1.2 & 0.24 & -0.4 & 0.68 & -2.6 & 0.01 & 0.8 & 0.45 & 0.18 & 5.57 \\
\hline Noncotund & -10.9 & 0.00 & -3.6 & 0.00 & -1.1 & 0.25 & -0.3 & 0.79 & -1.0 & 0.30 & -1.8 & 0.07 & 8.6 & 0.00 & -3.1 & 0.00 & 0.66 & 1.52 \\
\hline Lackvoid & 12.1 & 0.00 & -8.1 & 0.00 & -0.9 & 0.39 & -0.2 & 0.86 & -0.9 & 0.34 & -0.1 & 0.89 & 10.9 & 0.00 & -2.8 & 0.00 & 0.20 & 5.02 \\
\hline
\end{tabular}

The t-values show that the risk factors do significantly predispose individuals to infectious diseases, especially malaria, typhoid, chicken pox, and UTI. Table 4 provides a visual representation of the risk levels associated with each risk factor. Living in a tropical climate is evidently a major risk factor associated with tropical diseases. Being a street vendor predisposes people to infection; so is overcrowding and traveling to endemic regions. It is also instructive to note that some factors pose higher risks than others; for example, contact with an infected person poses a high risk of chicken pox infection ( $t=41.8$ [ $\left.{ }^{* \star \star}\right]$ ), while poor personal hygiene predisposes people to high risk of urinary tract infection $(t=23.6[\star \star \star])$. On the other hand, urbanization and homelessness, pose very low risks [*] across all the diseases, while low fluid intake, lack of void, and wearing non-cotton underwear only predispose individuals to few diseases ( 3 in each case).

Table 4: Disease-Risk Factor Relationships 


\begin{tabular}{|c|c|c|c|c|c|c|c|c|}
\hline & Malaria & Typhoid & Chicken Pox & Measles & Hepatitis B & Yellow Fever & UTI & Others \\
\hline Lwsocec & * & ** & * & & & * & & * \\
\hline Immig & * & & $\star \star$ & & * & & & ** \\
\hline Tropclim & ** & * & * & * & * & * & * & * \\
\hline Urbanzatn & & * & * & & * & & & * \\
\hline Strtvend & ** & * & * & & * & * & * & * \\
\hline Swgcont & * & ** & ** & & * & & ** & * \\
\hline Popershy & & ** & * & * & & & $\star \star \star$ & \\
\hline Ovrcrwd & * & * & * & * & * & & & ** \\
\hline Hmlsness & & * & & & * & & * & * \\
\hline Trendreg & ** & * & * & * & & & * & * \\
\hline Sknpunproc & * & ** & * & & * & & * & * \\
\hline Continfect & ** & & 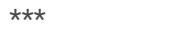 & & & & * & ** \\
\hline Lowfliud & ** & ** & * & & & & * & \\
\hline Noncotund & ** & * & & & & & * & * \\
\hline Lackvoid & $\star \star$ & * & & & & & ** & * \\
\hline
\end{tabular}

Key

\begin{tabular}{lll} 
Risk Level & Condition & Symbol \\
\hline Low & $2 \leq \mathrm{t}<10$ & $*$ \\
\hline Medium & $10 \leq \mathrm{t} \leq 20$ & $* \star$ \\
\hline High & $\mathrm{t}>20$ & $* \star \star$
\end{tabular}

\subsection{Discussion}

Risk factor analysis has the potential of providing prediction on the he prevalence, morbidity and mortality rates of tropical disease. It will also contribute to better diagnosis of tropical diseases as well as positively impact health agencies efforts in attempting to contain or prevent these conditions. Risk factors that predispose individuals to tropical diseases play major roles in determining actual disease states, prognosis after an attack of such disease, and the possibility of reinfections. Risk factors also determine how tropical diseases spread within a population, given that fact the such diseases do not offer permanent immunity to patients.

The authors of this study focused on epidemic prone and priority diseases in Nigeria (Federal Ministry of Health, 2005; Isere et al., 2015) such as malaria, typhoid, chicken pox, UTI, measles, yellow fever and hepatitis B The aforementioned tropical disease are diseases of utmost public health importance in Nigeria. Our results clearly indicate that malaria, UTI and typhoid are prevalent in Nigeria, and agrees with previous works done on disease prevalence in the country (Mordi et al., 2015; John et al., 2016; WHO EMRO, 2020). Findings from this study also agree that risk factors do significantly predispose individuals to tropical diseases and some factors pose higher risk than others.

The results of the study suggest that malaria, UTI and typhoid remain diseases of major public health importance in Nigeria. It has been shown, previously, that malaria and typhoid are at the top of the chart of the most overwhelming health problems facing the tropical and subtropical African countries with malaria alone claiming 213 million cases and over 380,000 deaths per year (WHO, 2019). Also, there are an estimated 11-21 million cases of typhoid fever and approximately 128,000-161,000 deaths annually (WHO, 2018a). In our study, majority of the cases of malaria diagnosed was high intensity, and for typhoid, moderate intensity. Most cases of UTI diagnosed were also high intensity attacks. This shows that these diseases represent a significant proportion of the disease burden in our environment.

Our results show that living in a tropical climate is by far a major risk factor associated with tropical diseases (malaria: $t=19.9$, typhoid: $t=-3.2$, chickenpox: $t=-6.5$ and typhoid: $t=12.7$ ). This finding can be understood from the standpoint of the lifecycle of the causative agent of the disease where warm climate plays a major role in the reproduction and propagation of the pathogens. It has been shown previously that temperature and moisture variables are the most 
important drivers for some tropical diseases like malaria (Midekisa et al., 2015; Mohammadkhani et al., 2016). It is not surprising therefore to see climate as a driver of these tropical diseases in Nigeria.

More so, level of exposure to infectious agents is a great determinant for a disease. It was found that being a street vendor predisposes people to infection; so does overcrowding and traveling to endemic regions. This is because these risk factors enhance contact with disease pathogens and possible disease establishment, and contact with pathogens have been found to increase the chances of disease occurrence. As observed in this study, contact with an infected person increased the risk of chicken pox by about 42 times. In the case of UTI, poor personal hygiene leads to exposure and prolonged contact with infectious agents. Poor hygiene therefore increased the risk of UTI up to about 24 timesas seen in this study. A previous study also reported the link between poor genital hygiene and development of UTIs (Amiri et al., 2009).

Risk levels varied by risk factors with some risk factors predisposing individuals to more diseases than others. Among the risk factors with low risk level were urbanization, low fluid intake, lack of voiding, and wearing non-cotton underwear predisposing individuals to few diseases, however, we were surprised to observe that homelessness also predisposed individuals to only few diseases. Previous studies have shown that homelessness predisposes individuals to a host of diseases (Raoult et al., 2001; Badiaga et al., 2008; Salez et al., 2014). We can attempt to explain this variation by looking at the geographical location where these studies were conducted. Raoult et al., (2001) carried out a review of studies done on the homeless, however only two countries were represented in the review. Further studies on how homelessness influence disease acquisition in tropical settings, especially in sub-Saharan Africa, are required to understand the true picture of the risk factor in tropical countries.

\section{Limitations}

We acknowledge the limitations of this study as follows: Some key tropical diseases that are common in Sub Saharan Africa were not included in the study including tuberculosis and upper and lower respiratory tract infections. Also, our study focused solely on Nigeria as a geographical entity for data collection. Although this limits the generalizability of study, we expect that our findings can be extrapolated to other regions of Africa and the tropics, since the risk factors focused on are similar in these areas. Based on the study findings, our ultimate goal is to attempt to develop the framework for a soft computing system, which will put into consideration tropical disease risk factors and tropical disease symptoms in order to facilitate easier and more efficient differential diagnosis of these diseases when they occur.

\section{Recommendations}

We recommend that significant effort be put into mitigating some of these risk factors which are modifiable. Low socio-economic class, homelessness and overcrowding as well as the negative effects of urbanization are modifiable risk factors. However, efforts at mitigating these rests largely on the governments as improvement in economic situations and creation of job opportunities for the public and private sector will lead to improved socioeconomic conditions. The government also has the task of providing potable water, free of sewage contamination to reduce risk of diseases like typhoid. On the other hand, poor hygiene, poor voiding, wearing non-cotton underwear and low fluid intake can be reduced at individual level. However these individuals must have proper information to affect their health behavior. Public Health Specialists and officials have the tasks of providing health education on these risk factors, and its effect on health to effect the necessary behavioural change. Finally, individuals migrating to or visiting endemic regions must ensure to be vaccinated or take chemoprophylaxis to prevent or reduce the severity of these tropical diseases.

\subsection{Conclusion}

The processes involved in diagnosing and differentiating tropical disease conditions by medical practitioners are complex and may sometimes be confusing; as a result of overlap and vagueness in symptoms presented by the different conditions as well as the fact that most of these conditions share same predisposing or risk factors. This builds the case for the exploration and understanding of the impact of different risk factors on the populations' predisposition to these conditions. Although, these risk factors as we have found in our study exert differential and discriminating influences in the causation, predisposition, and transmission of these conditions, understanding the individual risk factors for each condition will assist in better management and prevention of these conditions. We have attempted in this study to isolate and discriminate these risk factors according to how much influence they exert on each of the common tropical conditions studied.

Of the studied infectious diseases, malaria, UTI and typhoid fever were the most significant in terms of morbidity. The risk factors discussed and explored in this study also exert the highest influence in the spread of these conditions hence their relatively high incidence in the tropics. Our findings suggest that the predisposing risk factors to these conditions demand preferential attention by health authorities in these countries, if the health of people living in the tropics will be improved in order to reduce the incidence of these disease conditions.

\section{Declarations}

Ethics approval and consent to participate: Ethics approval for this study was obtained from the Mount Royal University, Clagary Human Research Ethics Board (HREB); Number: 100038

Consent for publication: The authors hereby give Springer the consent to publish this article.

Conflicts of interest: The authors hereby declare that there are no competing interests.

Funding: The funding for this research was received from the Faculty of Science and Technology Innovation Fund and the Research Grant Fund of Mount Royal University, Calgary. 
Acknowledgements: We thank Mount Royal University, Calgary for funding this research. We also appreciate the efforts of all our research assistants who worked tirelessly during data collection and analysis.

Data Availability: We have provided the data for this study as part of the manuscript submission.

Consent to Participate: We have provided the survey (including the recruitment script), which shows the consent to participate in the study.

Consent to Publish: The recruitment script includes consent to publish.

Code availability: Not applicable

Authors' Contributions:

- Faith-Michael Uzoka led the research, supervised data collection, contributed significantly to analysis, and contributed to the writing of the methodology and results sections of the paper

- Christie Akwaowo contributed significantly to the paper refinement and the discussion and conclusion sections

- Chinyere Nwafor Okoli contributed significantly to the literature review section

- Victory Ekpin contributed to the discussion and conclusion sections

- Chukwudi Nwokoro participated in data analysis and contributed to the results section

- Mohamed El Hussein contributed to the literature review and study limitations. In addition, he did the final paper edit

- Joseph Osuji contributed to the introduction and conclusion sections

- Flora Aladi contributed to the introduction section

- Boluwaji Akinnuwesi contributed to the literature review section

- Temitope Funmilola Akpelishi contributed to the introduction section

\section{References}

1. Abossie A, Yohanes T, Nedu A, Tafesse W, Damitie M. Prevalence of Malaria and Associated Risk Factors Among Febrile Children Under Five Years: A Cross-Sectional Study in Arba Minch Zuria District, South Ethiopia. Infection Drug Resistance. 2020;13:363-72. https://doi.org/10.2147/IDR.S223873.

2. Akuu JA, Danyi D, Dapaah C. Factors associated with poor food safety compliance among street food vendors in the Techiman Municipality of Ghana. Afr J Food Sci. 2017;11(3):50-7. https://doi.org/10.5897/AJFS2016.1510.

3. Alba S, Bakker MI, Hatta M, Scheelbeek PFD, Dwiyanti R, Usman R, Sultan AR, Sabir M, Tandirogang N, Amir M, Yasir Y, Pastoor R, van Beers S, Smits HL. Risk Factors of Typhoid Infection in the Indonesian Archipelago. PloS One. 2016;11(6):e0155286. https://doi.org/10.1371/journal.pone.0155286.

4. Amiri FN, Rooshan MH, Soliamani MJ. (2009). Hygiene practices and sexual activity associated with urinary tract infection in pregnant women. Eastern Mediterranean Health Journal, 15(1). http://www.emro.who.int/emhj-volume-15-2009/volume-15-issue-1/article11.html.

5. Aremu O. Socioeconomic differences in Yellow fever vaccine uptake in Togo: A multilevel analysis. International Journal of Infectious Diseases. 2018;73S:357-8.

6. Ayele AG, Gebre-Selassie S. (2013, January 3). Prevalence and Risk Factors of Hepatitis B and Hepatitis C Virus Infections among Patients with Chronic Liver Diseases in Public Hospitals in Addis Ababa, Ethiopia [Clinical Study]. ISRN Tropical Medicine; Hindawi. https://doi.org/10.1155/2013/563821.

7. Badiaga S, Raoult D, Brouqui P. Preventing and Controlling Emerging and Reemerging Transmissible Diseases in the Homeless. Emerg Infect Dis. 2008;14(9):1353-9. https://doi.org/10.3201/eid1409.082042.

8. Barnett ED. Yellow Fever: Epidemiology and Prevention. Clin Infect Dis. 2007;44(6):850-6. https://doi.org/10.1086/511869.

9. Chen LH, Wilson ME. Yellow fever control: Current epidemiology and vaccination strategies. Tropical Diseases Travel Medicine Vaccines. 2020;6(1):1. https://doi.org/10.1186/s40794-020-0101-0.

10. Chimbari MJ, Chirebvu E, Ndlela B. Malaria and schistosomiasis risks associated with surface and sprinkler irrigation systems in Zimbabwe. Acta Trop. 2004;89(2):205-13. https://doi.org/10.1016/j.actatropica.2003.09.015.

11. Daulagala SWPL, Noordeen F. Epidemiology and factors influencing varicella infections in tropical countries including Sri Lanka. VirusDisease. 2018;29(3):277-84. https://doi.org/10.1007/s13337-018-0459-z.

12. De Silva PM, Marshall JM. (2012, October 18). Factors Contributing to Urban Malaria Transmission in Sub-Saharan Africa: A Systematic Review [Review Article]. Journal of Tropical Medicine; Hindawi. https://doi.org/10.1155/2012/819563.

13. Deksissa T, Gebremedhin EZ. A cross-sectional study of enteric fever among febrile patients at Ambo hospital: Prevalence, risk factors, comparison of Widal test and stool culture and antimicrobials susceptibility pattern of isolates. BMC Infect Dis. 2019;19(1):288. https://doi.org/10.1186/s12879-0193917-3.

14. Dovjak M, Kukec A. (2019). Identification of Health Risk Factors and Their Parameters. In Dovjak M, Kukec A, editors, Creating Healthy and Sustainable Buildings: An Assessment of Health Risk Factors (pp. 83-120). Springer International Publishing. https://doi.org/10.1007/978-3-030-19412-3_3.

15. Eke CB, Ogbodo SO, Ukoha OM, Ibekwe RC, Asinobi IN, Ikefuna AN, Ibe BC. Seroprevalence and Risk Factors of Hepatitis B Virus Infection among Adolescents in Enugu, Nigeria. J Trop Pediatr. 2015;61(6):407-13. https://doi.org/10.1093/tropej/fmv035. 
16. Federal Ministry of Health. (2005). National policy on Integrated Disease Surveillance Response in Nigeria. Abuja: Federal Ministry of Health. 1-7. http://cheld.org/wp-content/uploads/2012/04/National-Policy-on-Integrated-Disease-Surveillance-and-Response.pdf.

17. Fernando S, Malavige G, Mallikahewa R, Sivayogan S, Jiffry M, Vitarana T, Liyanage N. Seroprevalence of varicella zoster virus infections in Colombo District, Sri Lanka. Indian J Med Sci. 2007;61(3):128. https://doi.org/10.4103/0019-5359.30747.

18. Flores-Mireles AL, Walker JN, Caparon M, Hultgren SJ. Urinary tract infections: Epidemiology, mechanisms of infection and treatment options. Nature Reviews Microbiology. 2015;13(5):269-84. https://doi.org/10.1038/nrmicro3432.

19. Foxman B. Urinary tract infection syndromes: Occurrence, recurrence, bacteriology, risk factors, and disease burden. Infect Dis Clin North Am. 2014;28(1):1-13. https://doi.org/10.1016/j.idc.2013.09.003.

20. Hagan JE, Takashima Y, Sarankhuu A, Dashpagma O, Jantsansengee B, Pastore R, Nyamaa G, Yadamsuren B, Mulders MN, Wannemuehler KA, Anderson R, Bankamp B, Rota P, Goodson JL. Risk Factors for Measles Virus Infection Among Adults During a Large Outbreak in Postelimination Era in Mongolia, 2015. J Infect Dis. 2017;216(10):1187-95. https://doi.org/10.1093/infdis/jix449.

21. Hamer DH, Angelo K, Caumes E, van Genderen PJJ, Florescu SA, Popescu CP, Perret C, McBride A, Checkley A, Ryan J, Cetron M, Schlagenhauf P. (2018). Fatal Yellow Fever in Travelers to Brazil, 2018. MMWR. Morbidity and Mortality Weekly Report, 67(11), 340-341.

https://doi.org/10.15585/mmwr.mm6711e1.

22. Henry J. (2005). Tropical And Equatorial Climates. Encyclopedia of World Climatology, 742-750. https://doi.org/10.1007/1-4020-3266-8_212.

23. Hosoglu S, Celen MK, Geyik MF, Akalin S, Ayaz C, Acemoglu H, Loeb M. Risk factors for typhoid fever among adult patients in Diyarbakir, Turkey. Epidemiol Infect. 2006;134(3):612-6. https://doi.org/10.1017/S0950268805005583.

24. Isere EE, Fatiregun AA, Ajayi IO. An overview of disease surveillance and notification system in Nigeria and the roles of clinicians in disease outbreak prevention and control. Nigerian Medical Journal: Journal of the Nigeria Medical Association. 2015;56(3):161-8. https://doi.org/10.4103/03001652.160347.

25. John AS, Mboto Cl, Agbo B. (2016). A review on the prevalence and predisposing factors responsible for urinary tract infection among adults. European Journal of Experimental Biology, 6(4). https://www.imedpub.com/abstract/a-review-on-the-prevalence-and-predisposing-factors-responsible-for-urinarytract-infection-among-adults-11526.html.

26. Keren R, Shaikh N, Pohl H, Gravens-Mueller L, Ivanova A, Zaoutis L, Patel M, deBerardinis R, Parker A, Bhatnagar S, Haralam MA, Pope M, Kearney D, Sprague B, Barrera R, Viteri B, Egigueron M, Shah N, Hoberman A. Risk Factors for Recurrent Urinary Tract Infection and Renal Scarring. Pediatrics. 2015;136(1):e13-21. https://doi.org/10.1542/peds.2015-0409.

27. Kotepui M, Kotepui KU. (2018, December 4). Impact of Weekly Climatic Variables on Weekly Malaria Incidence throughout Thailand: A Country-Based SixYear Retrospective Study [Research Article]. Journal of Environmental and Public Health; Hindawi. https://doi.org/10.1155/2018/8397815.

28. Kouadio IK, Kamigaki T, Oshitani H. Measles outbreaks in displaced populations: A review of transmission, morbidity and mortality associated factors. BMC International Health Human Rights. 2010;10(1):5. https://doi.org/10.1186/1472-698X-10-5.

29. Lemoine M, Nayagam S, Thursz M. Viral hepatitis in resource-limited countries and access to antiviral therapies: Current and future challenges. Future Virology. 2013;8(4):371-80. https://doi.org/10.2217/fvl.13.11.

30. Lim SS, Vos T, Flaxman AD, Danaei G, Shibuya K, Adair-Rohani H, AlMazroa MA, Amann M, Anderson HR, Andrews KG, Aryee M, Atkinson C, Bacchus LJ, Bahalim AN, Balakrishnan K, Balmes J, Barker-Collo S, Baxter A, Bell ML, ... Ezzati M. A comparative risk assessment of burden of disease and injury attributable to 67 risk factors and risk factor clusters in 21 regions, 1990-2010: A systematic analysis for the Global Burden of Disease Study 2010 . The Lancet. 2012;380(9859):2224-60. https://doi.org/10.1016/S0140-6736(12)61766-8.

31. Mackey TK, Liang BA, Cuomo R, Hafen R, Brouwer KC, Lee DE. Emerging and Reemerging Neglected Tropical Diseases: A Review of Key Characteristics, Risk Factors, and the Policy and Innovation Environment. Clin Microbiol Rev. 2014;27(4):949-79. https://doi.org/10.1128/CMR.00045-14.

32. Mandal BK, Mukherjee PP, Murphy C, Mukherjee R, Naik T. Adult susceptibility to varicella in the tropics is a rural phenomenon due to the lack of previous exposure. J Infect Dis. 1998;178(Suppl 1):52-4. https://doi.org/10.1086/514262.

33. Midekisa A, Beyene B, Mihretie A, Bayabil E, Wimberly M. Seasonal associations of climatic drivers and malaria in the highlands of Ethiopia. Parasites Vectors. 2015;8:339-9. https://doi.org/10.1186/s13071-015-0954-7.

34. Minardi D, d'Anzeo G, Cantoro D, Conti A, Muzzonigro G. Urinary tract infections in women: Etiology and treatment options. International Journal of General Medicine. 2011;4:333-43. https://doi.org/10.2147/IJGM.S11767.

35. Mogasale VV, Ramani E, Mogasale V, Park JY, Wierzba TF. (2018). Estimating Typhoid Fever Risk Associated with Lack of Access to Safe Water: A Systematic Literature Review. Journal of Environmental and Public Health, 2018, 9589208. https://doi.org/10.1155/2018/9589208.

36. Mohammadkhani M, Khanjani N, Bakhtiari B, Sheikhzadeh K. The relation between climatic factors and malaria incidence in Kerman, South East of Iran. Parasite Epidemiology Control. 2016;1(3):205-10. https://doi.org/10.1016/j.parepi.2016.06.001.

37. Mordi RM, Burke ME, Odjadjare EE, Enabulele SA, Umeh OJ. Prevalence of Urinary Tract Infections (UTI) Among Pregnant Women in University Of Benin Teaching Hospital (UBTH) Benin City, Nigeria. Journal of Asian Scientific Research. 2015;5(4):198-204. https://ideas.repec.org/a/asi/joasrj/2015p198204.html.

38. Murray CJ, Lopez AD. Global mortality, disability, and the contribution of risk factors: Global Burden of Disease Study. Lancet. 1997;349(9063):1436-42. https://doi.org/10.1016/S0140-6736(96)07495-8.

39. Obot OU, Inyang UG, Osuji J, Uzoka F-ME. (2014). A hybrid methodology for differential diagnosis of confusable diseases. Journal of Health \& Medical Informatics. https://www.hilarispublisher.com/proceedings/a-hybrid-methodology-for-differential-diagnosis-of-confusable-diseases-2408.html. 
40. Odei M-POK. Measles is in the news yet again. Journal of Family Medicine Primary Care. 2018;7(6):1166-8.

https://doi.org/10.4103/jfmpc.jfmpc_234_18.

41. Okojie PW, Isah EC. (2014, September 3). Sanitary Conditions of Food Vending Sites and Food Handling Practices of Street Food Vendors in Benin City, Nigeria: Implication for Food Hygiene and Safety [Research Article]. Journal of Environmental and Public Health; Hindawi.

https://doi.org/10.1155/2014/701316.

42. Omole D, Longe E, Adewum IK, Ogbiye A. Water resources use, abuse and regulation in Nigeria. Journal of Sustainable Development in Africa. 2010;5:35-44.

43. Pinsent A, Read JM, Griffin JT, Smith V, Gething PW, Ghani AC, Pasvol G, Hollingsworth TD. Risk factors for UK Plasmodium falciparum cases. Malaria Journal. 2014;13(1):298. https://doi.org/10.1186/1475-2875-13-298.

44. Raoult D, Foucault C, Brouqui P. Infections in the homeless. The Lancet Infectious Diseases. 2001;1(2):77-84. https://doi.org/10.1016/s14733099(01)00062-7.

45. Salez N, Benkouiten S, Sekene B, Charrel R, Brouqui P. Respiratory viruses within homeless shelters in Marseille, France. BMC Research Notes. 2014;7:81. https://doi.org/10.1186/1756-0500-7-81.

46. Shearer FM, Longbottom J, Browne AJ, Pigott DM, Brady OJ, Kraemer MUG, Marinho F, Yactayo S, de Araújo VEM, da Nóbrega AA, Fullman N, Ray SE, Mosser JF, Stanaway JD, Lim SS, Reiner RC, Moyes CL, Hay SI, Golding N. Existing and potential infection risk zones of yellow fever worldwide: A modelling analysis. The Lancet Global Health. 2018;6(3):e270-8. https://doi.org/10.1016/S2214-109X(18)30024-X.

47. Singh J, Datta KK. Epidemiological Considerations of the Age Distribution of Measles in India: A Review. J Trop Pediatr. 1997;43(2):111-5. https://doi.org/10.1093/tropej/43.2.111.

48. Socan M, Berginc N, Lajovic J. Varicella susceptibility and transmission dynamics in Slovenia. BMC Public Health. 2010;10:360. https://doi.org/10.1186/1471-2458-10-360.

49. Speakman MJ, Cheng X. Management of the complications of BPH/BOO. Indian Journal of Urology: IJU : Journal of the Urological Society of India. 2014;30(2):208-13. https://doi.org/10.4103/0970-1591.127856.

50. Storme 0, Tirán Saucedo J, Garcia-Mora A, Dehesa-Dávila M, Naber KG. (2019). Risk factors and predisposing conditions for urinary tract infection. Therapeutic Advances in Urology, 11. https://doi.org/10.1177/1756287218814382.

51. Tanthiphabha W, Sornchai P, Kosuwan P, Sutra S, Warachit B, Chup-Upprakarn S, Hutagalung Y, Weil J, Bock H. Effect of climatic factors and population density on varicella zoster virus epidemiology within a tropical country. The American Journal of Tropical Medicine Hygiene. 2000;64:131-6. https://doi.org/10.4269/ajtmh.2001.64.131.

52. Thang ND, Erhart A, Speybroeck N, Hung LX, Thuan LK, Hung CT, Ky PV, Coosemans M, D’Alessandro U. Malaria in central Vietnam: Analysis of risk factors by multivariate analysis and classification tree models. Malaria Journal. 2008;7(1):28. https://doi.org/10.1186/1475-2875-7-28.

53. Ugwuja E, Ugwu N. Seroprevalence of hepatitis B surface antigen and liver function tests among adolescents in Abakaliki, South Eastern Nigeria. The Internet Journal of Tropical Medicine. 2010;6(2):1726-32.

54. Uzoka F-ME, Akinnuwesi BA, Amoo T, Aladi F, Fashoto S, Olaniyan M, Osuji J. A Framework for Early Differential Diagnosis of Tropical Confusable Diseases Using the Fuzzy Cognitive Map Engine. World Academy of Science Engineering Technology International Journal of Computer Electrical Automation Control Information Engineering. 2016;10(2):346-53.

55. van Rijckevorsel GGC, Damen M, Sonder GJ, van der Loeff MFS, van den Hoek A. Seroprevalence of varicella-zoster virus and predictors for seronegativity in the Amsterdam adult population. BMC Infect Dis. 2012;12:140. https://doi.org/10.1186/1471-2334-12-140.

56. Vemula VN, Li L, Thoon KC, Chong CY, Tee NWS, Maiwald M, Tan NWH. Risk factors and clinical profile of measles infection in children in Singapore. Infection Disease Health. 2016;21(4):192-6. https://doi.org/10.1016/j.idh.2016.11.004.

57. Vos T, Lim SS, Abbafati C, Abbas KM, Abbasi M, Abbasifard M, Abbasi-Kangevari M, Abbastabar H, Abd-Allah F, Abdelalim A, Abdollahi M, Abdollahpour I, Abolhassani H, Aboyans V, Abrams EM, Abreu LG, Abrigo MRM, Abu-Raddad LJ, Abushouk Al, ... Murray CJL. Global burden of 369 diseases and injuries in 204 countries and territories, 1990-2019: A systematic analysis for the Global Burden of Disease Study 2019. The Lancet. 2020;396(10258):1204-22. https://doi.org/10.1016/S0140-6736(20)30925-9.

58. Weisberg SS. Vaccine preventable diseases: Current perspectives in historical context, Part II. Disease-a-Month: DM. 2007;53(10):467-528. https://doi.org/10.1016/j.disamonth.2007.09.009.

59. WHO. (2018a). Typhoid and other invasive salmonellosis (Vaccine-Preventable Diseases). World Health Organisation.

60. WHO. (2018b). Varicella. World Health Organization.

61. WHO. (2019). The "World malaria report 2019" at a glance. https://www.who.int/news-room/feature-stories/detail/world-malaria-report-2019.

62. WHO. (2020a). Fact sheet about Malaria. https://www.who.int/news-room/fact-sheets/detail/malaria.

63. WHO. (2020b). Yellow fever. https://www.who.int/news-room/fact-sheets/detail/yellow-fever.

64. WHO EMRO. (2020). Neglected tropical diseases. http://www.emro.who.int/health-topics/tropical-diseases/.

\section{Figures}




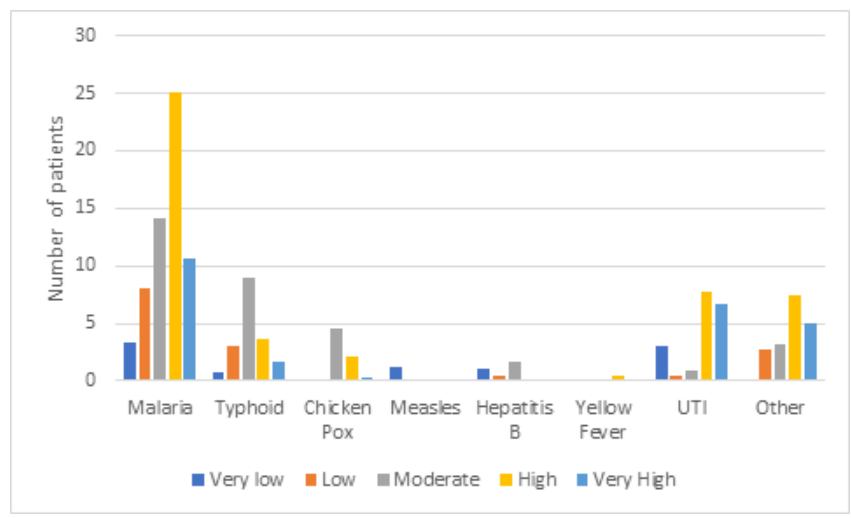

Figure 1

Level of intensity per disease diagnosed

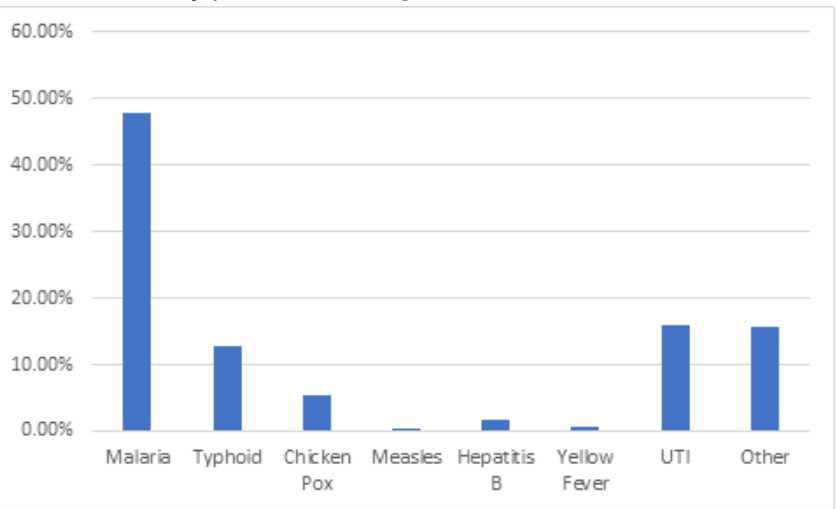

Figure 2

Disease percentage prevelance 